\title{
Early Myocardial Infarction
}

\section{A Feasable Histologic Diagnostic Procedure}

\author{
José Milei, M.D., Ph.D. and Rubén Storino, M.D.
}

\section{SUMMARY}

The Barbeito-López trichrome stain (BLTS) was compared with hematoxylin and eosin ( $\mathrm{HE}$ ), the basic fuchsin picric acid (BFP) and nitro-blue tetrazolium (NBT) dye tests. Two types of hearts were studied: a) myocardial necrosis induced by isoproterenol (ISP) in rats and b) human hearts with early coagulation necrosis (Early $\mathrm{CN})$. The BLTS was much more sensitive than $\mathrm{HE}$ for diagnosis of Early CN in rats. By 24 hours, both BLTS and HE showed established coagulation necrosis (Established CN) although BLTS did so more clearly. In human material BLTS was a useful indicator of Early CN. It showed patchy areas of coagulation necrosis in the cytoplasm of damaged myocardial cells which were not visualized with HE. Normal myocardium remained green or pale blue. Early CN appears as patchy yellow areas while the remainder of the cytoplasm stains green. Established CN appears "golden yellow" or "orange yellow".

\section{Additional Indexing Words:}

Early myocardial damage Early necrosis Contraction bands Isoproterenol Myocardial infarction

\begin{abstract}
A CCURATE diagnosis of early myocardial infarction is of great interest in modern cardiac pathology. Buss compared methods to delineate myocardial infarcts within 12 hours after the onset of the ischemic episode ${ }^{11}$ and found that a combination of the following four techniques was the most reliable: Selye's acid fuchsin, ${ }^{21}$ hematoxylin and eosin, acridine orange fluorescence on frozen sections ${ }^{3 \prime}$ and gross nitro-blue tetrazolium (NBT).4) Other authors combine conventional histologic evaluation with triphenyl-tetrazolium chloride staining (TTC), ${ }^{3,5)}$ basic fuchsin picric acid on paraffin sections

From the Pathology Section, Institute of Cardiology of the National Academy of Medicine, Buenos Aires, Republica Argentina.

Address for reprint: Dr. José Milei, Hospital Instituto de Cardiologia, Coronel Diaz 2423, 1425-Buenos Aires, Republica Argentina.

This study was supported in part by a research grant from Fundation Hermenegilda Pombo de Rodriguez.

Received for publication April 15, 1985.
\end{abstract}


$(\mathrm{BFP})^{6)}$ and determination of myocardial $\mathrm{K}+/ \mathrm{Na}^{+}$ratios. ${ }^{7)}$ More recently, "wavy fibers" were described as simple histologic changes that were said to be diagnostic of early infarction on routine sections. ${ }^{81}$

The methods listed above have proven satisfactory when applied to the evaluation of experimental myocardial infarction. Unfortunately, the ability of the same methods to delineate early human myocardial necrosis is greatly impaired by the obligatory period of autolysis commonly present in human autopsies. Thus, there still exists a need for a simple and reliable method that will delineate early human myocardial infarcts in paraffin sections processed routinely.

Our laboratory has used a stain described in 1946 by Barbeito-López ${ }^{91}$ as an all-purpose trichrome stain. In the course of studies of isoproterenolinduced cardiac lesions in rats, $\left.{ }^{10}\right)$ we noticed that myocardial necrosis was clearly delineated by this method and decided to carry out a systematic evaluation to determine its potential application in the histopathologic evaluation of ischemic myocardial lesions. This paper reports comparative studies using the Barbeito-López trichrome stain (BLTS), hematoxylin and eosin and the basic fuchsin picric acid and nitro-blue tetrazolium stains. We will show that the BLTS is a simple and reliable method for the early histologic diagnosis of both experimental and human myocardial infarction.

\section{Materials and Methods}

1. Experimental myocardial necrosis induced by isoproterenol

Forty Wistar rats weighing from 180 to $200 \mathrm{Gm}$ were used. Animals were injected intraperitoneally with isoproterenol sulphate (ISP) at a dose of $10 \mathrm{mg} / \mathrm{Kg}$, and sacrified $30 \mathrm{~min}$ (Group $\mathrm{A}, \mathrm{n}=20$ ) or 24 hours later (Group $B, n=20$ ), under light ether anesthesia. The hearts were transversely sectioned every $1 \mathrm{~mm}$. The cardiac slices were processed for histological, histochemical and ultrastructural evaluation (see below). A similar group of rats $(n=40)$, injected with distilled water and sacrificed at similar times, was used as controls. Although the sacrifice of animals at $30 \mathrm{~min}$ and 24 hours leaves a long period in which numerous changes develop in the myocardium, they are nevertheless appropriate to show examples of early (30 min) and established (24 hours) myocardial necrosis.

\section{Human myocardial infarction}

Forty human hearts with myocardial infarcts in early stages of evolution ( 3 to 48 hours old) were studied. In all instances, autopsies were performed within 6 hours of death. 
The hearts were serially cross-sectioned in $5 \mathrm{~mm}$ thick slices. To delineate accurately the area of the infarct all slices were stained with NBT. ${ }^{4}$ All slices, including infarcted and normal areas, were measured by planimetry and the percentage of necrotic tissue calculated. Each slice was embedded in paraffin and sectioned with a sliding microtome. The macrosections were stained with special techniques (see below). Employing the same method, an equal number of hearts of individuals who died of extracardiac diseases were examined. Patients in this group were of similar sex and age.

\section{Histologic studies}

Hematoxylin and eosin, $\mathrm{BFP}^{61}$ and BLTS were used. All tissue had been fixed in buffered, neutral 10\% formalin and embedded in paraffin. Sections were cut at a thickness of $6 \mu \mathrm{m}$.

\section{$B L T S^{91}$}

Staining solutions: 1) acetic fuchsin solution: Zichl's fuchsin solution, $10 \mathrm{cc}$; glacial acetic acid, $0.2 \mathrm{cc}$; distilled water, $100 \mathrm{cc} ; 2)$ acetic formalin solution: formaldehyde, $37-40 \% 4.0 \mathrm{cc}$; glacial acetic acid, $0.2 \mathrm{cc}$; distilled water, $100 \mathrm{cc}$; 3) molybdic acid-aniline blue methyl orange solution: to $100 \mathrm{cc}$ of distilled water in a $250 \mathrm{cc}$ Erlenmeyer flask add $1 \mathrm{Gm}$ of molybdic acid, shake vigorously and heat gently for $5 \mathrm{~min}$. Add $0.5 \mathrm{Gm}$ of water soluble aniline blue and dissolve. Add methyl orange in excess until a deposit forms in the bottom of the flask. Filter.

Staining procedure: Deparaffinize and hydrate to water. Stain in acetic fuchsin solution. Wash vigorously in tap water to remove excess solution. Fix color in acetic formalin solution, up to $3 \mathrm{~min}$. Place sections, in Coplin jar containing the solution, agitate and renew solution after 4 or 5 uses. The color changes from red to pale violet. Wash in tap water. Stain in molybdic acid-aniline blue methyl orange solution $-30 \mathrm{sec}$ to $1 \mathrm{~min}$. Wash in tap water-rapid. Dehydrate (rapid), clear and mount. Disregard the color clouds that appear in the $95 \%$ alcohol.

Appearance of tissue: Nuclei, violet red; cytoplasm, green to pale blue; reticulum fibers, deep blue; collagen, brilliant green; red blood cells, brilliant orange; bacteria, violet red.

The serial sections stained by each technique were compared carefully to determine the corresponding areas. The serial sections were examined by each author separately and later compared. The following features were evaluated: presence or absence of myocardial necrosis, types of necrotic lesions and extent of necrosis.

The relative volume of the necrotic areas was assessed by stereologic differential point counting methods ${ }^{11)}$ (experimental material) and the results were statistically evaluated using the Student's test. Gross and microscopical 
mapping of necrotic areas were compared for the human material only.

\section{Histochemical studies}

Histochemical methods for succinic-dehydrogenase ${ }^{12), 13)}$ were performed on the rat myocardia. Estimates of histochemical enzymes activities were graded from traces $( \pm)$ to $4+$.

\section{Ultrastructural studies}

For electron microscopy, specimens of the rat myocardia were cut in cubes of $0.5 \mathrm{~mm}$ in size, fixed in phosphate-buffered osmium tetroxide, dehydrated in a graded series of alcohols and propylene oxide, and embedded in Araldite. Sections were cut with glass knives on an LKB ultramicrotome. From each block, several $1-\mu \mathrm{m}$ sections were mounted on glass slides stained with $1 \%$ toluidine blue, examined by light microscopy and those blocks showing lesions were selected for ultrathin sectioning. The tissue was taken from areas of staining or lack of staining by the various histological techniques employed. Ultrathin sections were mounted on copper grids, stained with uranyl acetate and examined with a Phillips 200 electron microscope.

\section{Results}

For the purposes of this study, lesions with myocardial necrosis were further subdivided as early and established coagulation necrosis. We defined

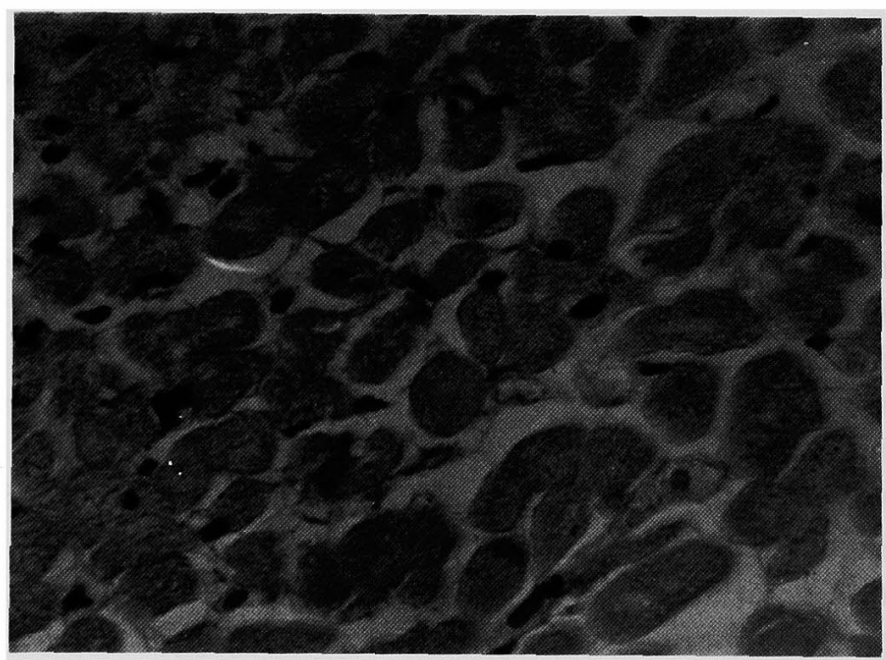

Fig. 1. "Early coagulation necrosis" is shown in a single fiber. Cytoplasmic changes consist of a homogeneous appearance of the cytoplasm and yellow staining with the Barbeito-López trichrome stain. Normal myofibers are green. $\times 380$. Human material. Border zone of a myocardial infarct, 6 hours old. 
early coagulation necrosis (early $\mathrm{CN}$ ) as patchy cytoplasmic alterations in a single fiber with minor nuclear changes. The cytoplasmic changes consist of patchy homogenization of the cytoplasm with a relative loss of cross-striations or increased granularity of cytoplasm and thinning and waviness of fibers or hypereosinophilia ${ }^{8,14), 15)}$ (Fig. 1). Included in this category are the lesions known as "contraction bands", i.e. transverse strips of hypereosinophilic cytoplasm $^{14)}$ (Fig. 2). Vascular congestion and stasis, interstitial hemorrhage, and margination of neutrophils in vessels (with infiltration into interstitial spaces) were also considered as extramyocardial features of early $\mathrm{CN}^{88,14), 15)}$

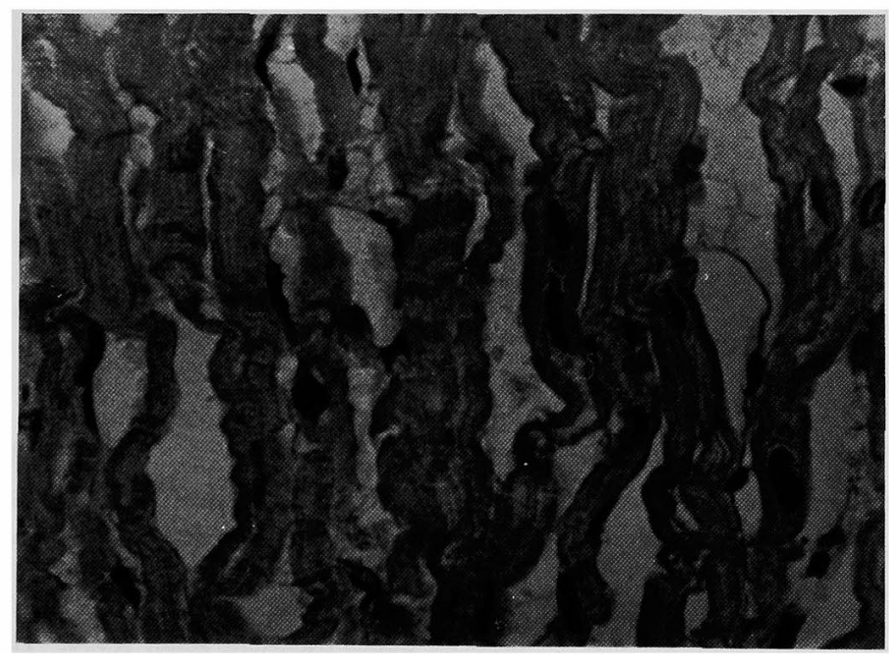

Fig. 2. "Contraction bands" are shown as transverse strips of yellow cytoplasm. Barbeito-López trichrome stain. $\times 380$. Human material. Myocardial infarct, 12 hours old.

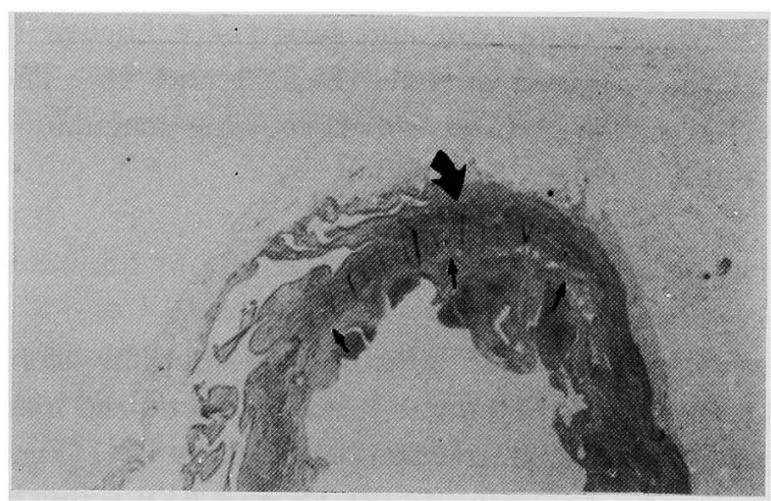

Fig. 3. "Established coagulation necrosis". Myofibers are stained yellow. Anterior wall of a macrosection-Barbeito-López trichrome stain. Human material. Myocardial infarct, 1 day old. 


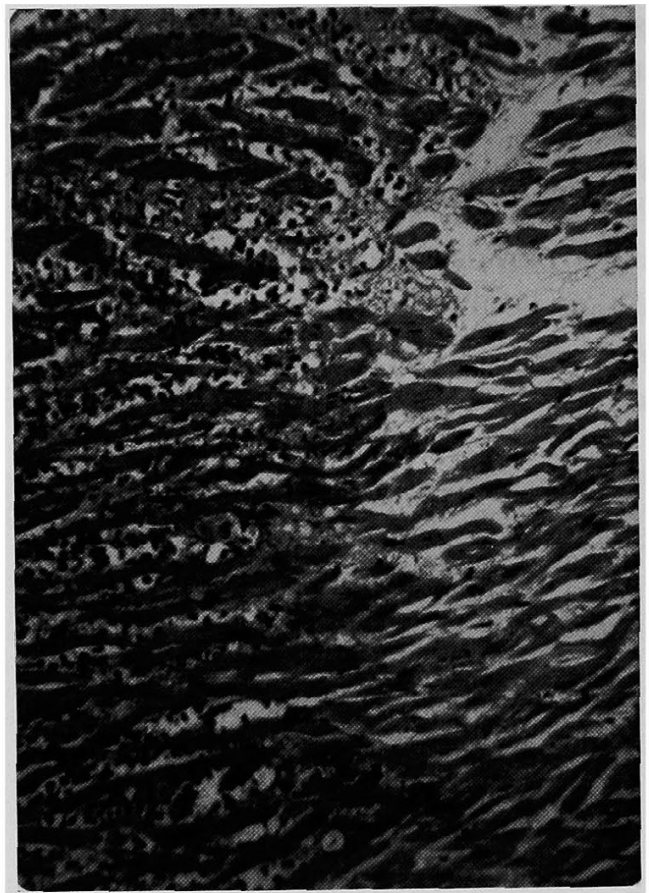

Fig. 4. "Established coagulation necrosis" with homogenization of the entire cytoplasm and nuclear lysis surrounded by polymorphonuclear infiltration is shown at the left. Myofibers are stained "golden yellow" while at the right " early coagulation necrosis" is stained paler. In this case, the polymorphonuclear infiltrates clearly limit the bulk of the infarct from the " early coagulation necrosis". Barbeito-López trichrome stain. $\times 350$. Human material. Myocardial infarct, 3 days old.

Established coagulation necrosis (established GN) was defined as a homogenous appearance of the entire cytoplasm and progressive nuclear lysis, visible on hematoxylin and eosin-stained sections (Figs. 3 and 4). The BLTS stains normal myofibers green, whereas myofibers showing coagulation necrosis shift to a "golden yellow" color.

\section{A. Experimental material}

\section{Light microscopy}

Group A (ISP-sacrificed at $30 \mathrm{~min}$ ). Myocardial necrosis comprised $6.8 \pm 0.9 \%$ of the myocardial volume. It was characterized by subendocardial fibrillar homogenization and contraction bands (early CN) (Fig. 5). Contraction bands were clearly shown by the BLTS and BFP stains but only rarely by hematoxylin and eosin.

Group B (ISP-sacrificed at 24 hours). Early and established zones of 


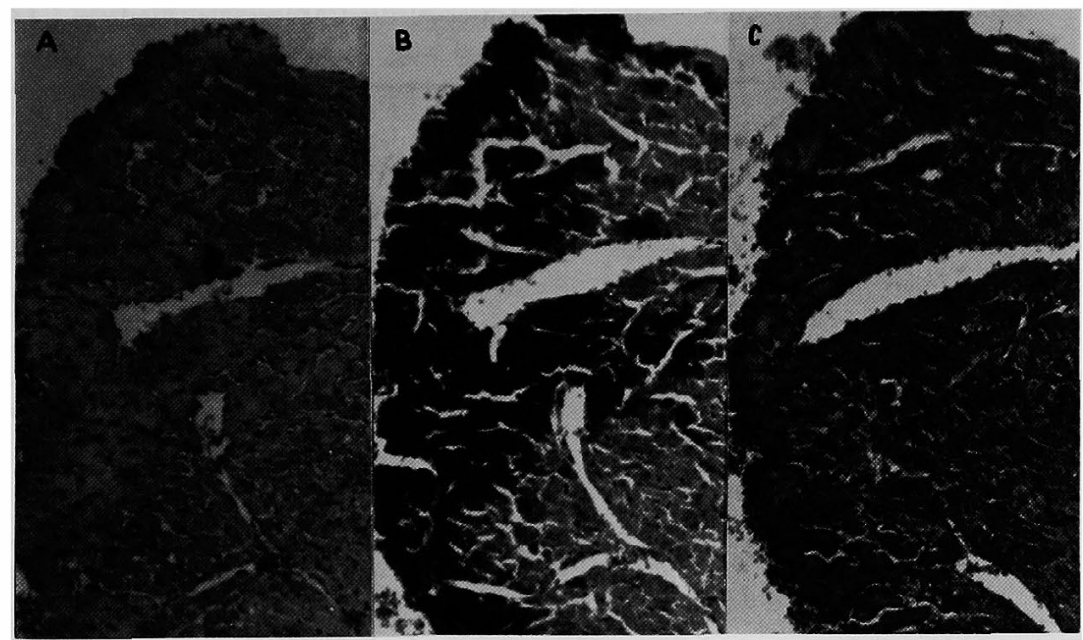

Fig. 5. Subendocardial cytoplasm homogenization is clearly shown by the BLTS and BFP stains but not clearly with hematoxylin and eosin. Serial sections. A: hematoxylin-eosin; B: BFP; C: BLTS. $\times 343$. Experimental material. Myocardium of rat injected with isoproterenol and sacrificed after $30 \mathrm{~min}$.

CN represented $25.1 \pm 1.4 \%$ of myocardial volume. Sections revealed focal established CN, especially in the apex of the left ventricle, and a homogeneous appearance and contraction bands in cells close and distant to areas of established CN. Mononuclear cell infiltrates, hemorrhage and congestion were found surrounding these zones.

Although all three stains showed the ISP-induced lesions at 24 hours, areas of early and established $\mathrm{CN}$ were demonstrated with greatest clarity and contrast by the BLTS and BFP methods (Table I).

Control group. There were a few small areas of early $\mathrm{CN}$, comprising $0.4 \pm 0.1 \%$ of the myocardial volume $(p<0.001)$. These erratic zones were related to stress during the injection and were clearly detected by the BLTS and BFP stains.

\section{Histochemistry}

The myocardium of control rats showed normal amounts of succinic dehydrogenase $(2+$ to $3+)$. A decrease $(1+$ to $2+)$ in succinic dehydrogenase staining was observed in Group A (after $30 \mathrm{~min}$ ). In some areas, an increase $(4+)$ was noted. This effect could be explained by a metabolic rate increase due to ISP action. At 24 hours (Group B), a generalized decrease $(1+)$ in myocardial succinic dehydrogenase staining was observed, whereas a complete absence of the enzyme was seen in necrotic areas (Table I). 
Table I. Histologic, Histochemical and Ultrastructural Myocardial Findings in Control Rats and Rats Injected with Isoproterenol

\begin{tabular}{|c|c|c|c|c|c|}
\hline & $\begin{array}{l}\text { Hematoxylin- } \\
\text { eosin }\end{array}$ & $\begin{array}{l}\text { Barbeito-López } \\
\text { trichrome stain }\end{array}$ & $\mathrm{BFP}$ & $\begin{array}{c}\text { Succinic- } \\
\text { dehydrogenase } \\
\text { (after } 24 \text { hours) }\end{array}$ & $\begin{array}{l}\text { Ultrastructural } \\
\text { findings }\end{array}$ \\
\hline $\begin{array}{l}\text { Control } \\
\text { myocardium }\end{array}$ & $\begin{array}{l}\text { Cytoplasm: } \\
\text { pink } \\
\text { Nuclei : blue }\end{array}$ & $\begin{array}{l}\text { Cytoplasm : } \\
\text { green to } \\
\text { pale blue } \\
\text { Nuclei : violet } \\
\text { red }\end{array}$ & Yellow & Abundant & Normal \\
\hline $\begin{array}{l}\text { Early } \\
\text { coagulation } \\
\text { necrosis }\end{array}$ & $\begin{array}{l}\text { Rare contrac- } \\
\text { tion bands } \\
\text { Hyper- } \\
\text { eosinophilia }\end{array}$ & $\begin{array}{l}\text { Gytoplasm : } \\
\text { pale yellow } \\
\text { Nuclei : } \\
\text { variable } \\
\text { violet red }\end{array}$ & Red & Decreased & $\begin{array}{l}\text { Sarcoplasmic and } \\
\text { mitochondrial } \\
\text { swelling } \\
\text { Focal loss of } \\
\text { glycogen } \\
\text { Subsarcolemmal } \\
\text { blebs }\end{array}$ \\
\hline $\begin{array}{l}\text { Established } \\
\text { coagulation } \\
\text { necrosis }\end{array}$ & $\begin{array}{l}\text { Cytoplasmatic } \\
\text { homogeni- } \\
\text { zation } \\
\text { Nuclear lysis }\end{array}$ & $\begin{array}{l}\text { Golden yellow } \\
\text { cytoplasm } \\
\text { Nuclear lysis }\end{array}$ & Red & Absent & $\begin{array}{l}\text { Amorphous mito- } \\
\text { chondrial densities } \\
\text { Membrane dis- } \\
\text { ruption } \\
\text { Marked glycogen } \\
\text { loss }\end{array}$ \\
\hline
\end{tabular}

\section{Electron microscopy}

In animals sacrificed at $30 \mathrm{~min}$, after the injection of ISP, segmental hypercontraction with a reduction of the sarcomeric length and a widening of $\mathrm{Z}$ bands ("contraction bands") was observed. At 24 hours after ISP injection, ruptures of cardiocytes and of the sarcolemmal membrane, as well as decreased glycogen content were noted. Mitochondria showed electron densities and granular deposits and presented a swollen appearance. "Contraction bands" and myofibrillar relaxation and fragmentation were common findings. Ultrastructural findings are compared to histological and histochemical data in Table $\mathrm{I}$. These data were obtained from corresponding surfaces of myocardium.

\section{B. Human material}

The mean infarcted left ventricular volume varied from 10 to $61 \%$ with a mean infarcted volume of $25.1 \pm 14.6 \%$. The appearance of the human infarcts was comparable to that described by others using hematoxylin-eosin ${ }^{15}$ ) and NBT, ${ }^{14)}$

A close correlation existed between the lesions shown by NBT and BLTS. BLTS showed areas of early CN which were not visualized with hematoxylineosin, but grossly delineated with NBT. Differences between values of gross 
(NBT) and microscopical mapping (BLTS) obtained from paraffin-embedded macrosections were always less than $10 \%$. By contrast, the BFP stain gave unreliable and often contradictory results. Details of stains in AMI are summarized in Table II.

The BLTS was highly reliable for identifying myocardial necrosis. Normal myocardium remained green or pale blue. Early CN appears as patchy yellow areas while the remainder of the cytoplasm stains green (Figs. 1 and 2). Established CN appears "golden yellow" or "orange yellow" (Fig. 4). With BLTS an interesting picture was observed: the bulk of the infarct

Table II. Histologic and Histochemical Findings in Human Myocardial Infarction ( 3 to 48 hours old)

\begin{tabular}{l|c|c|c|c}
\hline & \multicolumn{1}{|c|}{$\begin{array}{c}\text { Hematoxylin- } \\
\text { eosin }\end{array}$} & $\begin{array}{l}\text { Barbeito-López } \\
\text { trichrome stain }\end{array}$ & NBT & BFP \\
\hline \begin{tabular}{l|l|l|} 
Normal \\
myocardium
\end{tabular} & Cytoplasm : pink & $\begin{array}{l}\text { Cytoplasm : green } \\
\text { to pale blue }\end{array}$ & $\begin{array}{l}\text { Intracellular } \\
\text { dark blue dots }\end{array}$ & $\begin{array}{l}\text { Cytoplasm : } \\
\text { yellow or red }\end{array}$ \\
\cline { 2 - 3 } $\begin{array}{l}\text { Early coagula- } \\
\text { tion necrosis }\end{array}$ & Contraction bands & $\begin{array}{l}\text { Cytoplasm : patchy } \\
\text { yellow areas } \\
\text { Nuclei : variable } \\
\text { violet red }\end{array}$ & Unstained & Red \\
\hline $\begin{array}{l}\text { Established } \\
\text { coagulation } \\
\text { necrosis }\end{array}$ & Homogenization & $\begin{array}{l}\text { Cytoplasm : golden } \\
\text { yellow or orange } \\
\text { yellow } \\
\text { Nuclear lysis }\end{array}$ & Unstained & Yellow \\
\hline Nuclear lysis & &
\end{tabular}

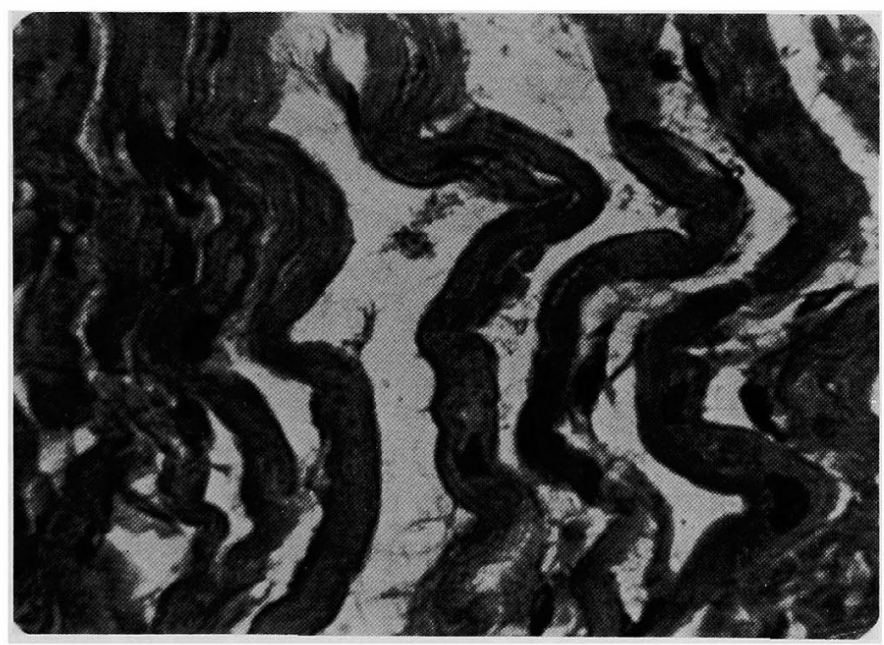

Fig. 6. Wavy fibers. Myofibers are stained yellow in a patchy manner, and the normal green color has disappeared in almost all the fibers. BarbeitoLópez trichrome stain. $\times 692$. Human material. Myocardial infarct, 6 hours old. 


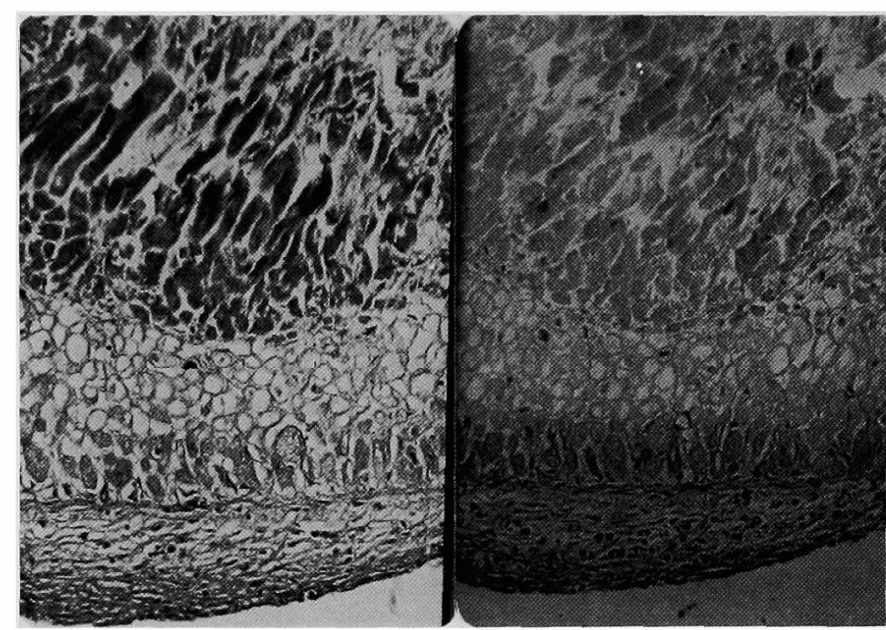

Fig. 7. Transmural infarction. On the top: established coagulation necrosis; the fibers are stained golden yellow. On the bottom: progressive myocytolysis of several myofibers corresponding to the 3 or 4 cell layers of subendocardium. The relatively preserved myofibers are stained green with the Barbeito-López trichrome stain. $\times 378$. Human transmural infarct, 2 days old. These serial sections belong to HE (on the right) and BLTS (on the left).

stained golden yellow (established CN) whereas its periphery contained myocytes which showed focal yellow staining in the cytoplasm (early CN, Fig. 4). This change was not visible on $\mathrm{H}$ and $\mathrm{E}$.

In most cases, "wavy fibers" appeared " pale yellow" in a patchy manner (Fig. 6). " Contraction bands" were also stained yellow and were easier to identify and more frequently demonstrated than with $\mathrm{H}$ and $\mathrm{E}$. In all infarcts, the 1 or 2 cell thick layers of subendocardial fibers just beneath the endocardium were preserved and stained green with the BLTS, while deeper ones were necrotic and stained yellow (Fig. 7).

\section{Discussion}

In this study, we evaluated an all purpose trichrome stain described by Barbeito-López ${ }^{9)}$ as a simple histologic method for the early diagnosis of myocardial necrosis in human and experimental animal hearts. Results of this study indicate that BLTS is a sensitive marker of early and established coagulation necrosis.

The Barbeito-López trichrome stain was much more useful than hematoxylin and eosin in depicting myocardial damage 30 min after the injection of isoproterenol sulphate in rats (early coagulation necrosis). By 24 hours, 
both BLTS and $\mathrm{H}$ and $\mathrm{E}$ showed established coagulation necrosis, although the former did so more clearly and with better contrast.

Based on our experience with 40 human myocardial infarcts studied 3 to 48 hours after death, the Barbeito-López trichrome stain is a valuable and sensitive indicator of early ischemic damage. It showed patchy areas of early $\mathrm{CN}$ which were not visualized with $\mathrm{H}$ and $\mathrm{E}$ but grossly indicated with NBT. More advanced lesions, including contraction bands and complete homogenization of the cytoplasm, were shown by the Barbeito-López trichrome and hematoxylin and eosin stains, although the changes were more clearly defined with the former.

As claimed for other non-enzymatic methods, ${ }^{16)}$ results obtained with BLTS may be due to a diminution of intracellular $\mathrm{pH}^{(17)-19)}$ and membrane permeability alterations with penetration of different elements as occurs in early myocardial injury. ${ }^{201-25)}$

The results for BLTS and $\mathrm{H}$ and $\mathrm{E}$ were compared to those obtained by staining serial sections with the basic fuchsin picric acid (BFP) method of Lie at al.6) Although the BFP method was as sensitive as BLTS in detecting isoproterenol-induced myocardial damage in rat hearts, it gave erratic, poorly reproducible and often contradictory results when applied to the evaluation of human myocardial ischemic damage. This suggests that the obligatory period of autolysis in human hearts interferes with the ability of the BFP stain to reliably detect early myocardial necrosis, or that the isoproterenol animal model for myocardial necrosis is not comparable to human myocardial infarction.

This study also emphasizes the value of the routine use of paraffin-embedded macrosections of the cardiac ventricles in comparative studies and in detecting unsuspected lesions that might have been missed by random sectioning of the myocardium. Thus, the histologic macrosections used in this work allowed us to survey, millimeter by millimeter, approximately $120 \mathrm{~cm}^{2}$ of myocardium in each heart. Minor early changes, such as hypereosinophilia and edema, become quite apparent when the entire cross-section of myocardium is available for comparison ${ }^{26}$ and the sections are useful for quantification. In fact, it is more reliable to measure the infarct in one complete section than to attempt to reconstruct its borders and estimate its size from at least four to seven common histological sections. ${ }^{27}$

Recently, Carle ${ }^{28)}$ described a method for demonstrating myocardial necrosis by changes in the autofluorescence of routine hematoxylin and eosin stained sections. However, to our judgement, it is an uncritical evaluation of a new method. In fact, no attempt has been made to determine the interval nccessary for the autofluorescence to become apparent and facilities 
have not been available to study and standardize the technique in animals. In addition, it lacks a simple control procedure. In all human myocardial infarcts, the 1 or 2 cell thick layers of muscle just beneath the endocardium are always spared because these cells get their oxygen from the ventricular lumen or the Thebesian vessels or they are Purkinje cells. One would hope that these cells are preserved and the dceper ones are changed with the autofluorescence technique. Obviously, with BLTS it occurs in all cases, as shown in Fig. 7.

In conclusion, the Barbeito-López trichrome stain is a valuable method for the routine, early diagnosis of myocardial necrosis in both human and experimental material. Based on our experience, we believe that the BarbeitoLópez trichrome stain deserves a full-scale trial as a sensitive index of early myocardial damage in order to determine its ultimate place among histologic methods used for this purpose.

\section{ACKNowledgments}

The authors wish to express their acknowledgments to Dr. Daniel Alonso (Cornell University, New York) for the revision of the manuscript and to Mrs. N. Borasit for her valuable technical assistance.

\section{ReFERENCES}

1. Buss H: Histochemische Fruehdiagnose des experimentellen Herzinfarktes unter Beruecksichtigung der Autolyse. Beitr Pathol Anat 140: 257, 1970

2. Poley RW, Fobes CD: Fuchsinophilia in early myocardial infarction. Arch Pathol (Chicago) 77: 325, 1964

3. Knight T: The post-mortem demonstration of early myocardial infarction. Med Sci Law 5: 31,1965

4. Nachlas MM, Shnitka TK: Macroscopic identification of early myocardial infarcts by alterations in dehydrogenase activity. Arn $J$ Pathol 42: 379, 1963

5. Titus JL: Heart and vascular system. in Current Methods of Autopsy Practice, ed by Lee WT, WB Saunders Co, Philadelphia, p 61, 1972

6. Lie JT, Holleg KE, Kampa WR, Titus JL: New histochemical method for morphologic diagnosis of early stages of myocardial ischemia. Mayo Clin Proc 46: 319, 1971

7. McVie JG: Post-mortem detection of inapparent myocardial infarction. J Clin Pathol 23: 203,1970

8. Bouchardy B, Majno G: Histopathology of early myocardial infarcts. New approach. Am J Pathol 74: 301, 1974

9. Barbeito-López J: A new trichrome stain. Am J Clin Pathol Tech 16: 53, 1946

10. Milei J, Rapaport M: Localization by autoradiography of tritiated isoproterenol in " infarct-like" lesions of rat myocardium. Am Heart J 92: 351, 1976

11. Weibel ER: Principles and methods of the morphometric study of the lung and other organs. Lab Invest 12: 131, 1963

12. Pearse AG: Histochemistry, Churchill-Livingstone, Edinburgh, London, 1972

13. Burstone MS: Modifications of histochemical techniques for the demonstration of cytochrome oxidase. J Histochem Cytochem 9: 59, 1961 
14. Reichenbach DD, Benditt EP: Myofibrillar degeneration, a response of the myocardial cell to injury. Arch Pathol 85: 189, 1968

15. Mallory GK, White PD, Salcedo-Salgar J: The speed of healing of myocardial infarction. A study of the pathologic anatomy in seventy-two cases. Am Heart J 18: 647, 1939

16. Musy JP, Haag JR: Diagnostic de nécroses myocardiques au stade initial par des colorations simples. Ann Anat Pathol 22: 97, 1977

17. Schneider D, Urbaszek W: Biochemisch-histochemische Befunde am Herzen bei akuter Hypoxie und Ischamie bzw. Myokardinfrazierung. Zschr inn Med 29: 180, 1974

18. Kunze KD, Schuh D, Arnold F, Hermann WR: In vitro-Messung der pH-Anderungen am experimentellen Rattenherzinfarkt mit der Glaselektrode. Virchows Arch Abt B 1: 80, 1968

19. Scheuer J, Lai F: Early changes in myocardial hypoxia: relations among mechanical function, $\mathrm{pH}$ and intracellular redox states. in Recent Advances in Studies on Cardiac Structure and Metabolism, ed by Harris P, Bing RJ, Fleckenstein A, Vol 7, Urban Schwarzenberg, München, Berlin, Wien, p 237, 1976

20. Flear CTG, Riemersma RA, Mandra G, Talbot R: Changes in myocardial water and solutes after ischemia. in Recent Advances in Studies on Cardiac Structure and Metabolism, ed by Harris P, Bing RJ, Fleckenstein A, Vol 7, Urban Schwarzenberg, München, Berlin, Wien, p 297, 1976

21. OMS diagnostic histochemique et anatomo-pathologique de la cardiomyopathie ischémique aigüe. Org Mond Santé Rapp Techn N 141,1970

22. Heilman K, Voelk A, Belsch U: Frühdiagnose des Myokardinfarkts. Arztl Forsch 26: 207, 1972

23. Zugibe FT Jr, Zugibe FT: Fuchsinophilia and fuchsinorrhagia staining techniques. Arch Pathol (Chicago) 96:243, 1973

24. Rona G, Boutet N, Huttner I: Membrane permeability alterations as manifestation of early cardiac muscle cell injury. in Recent Advances in Studies on Cardiac Structure and Metabolism, ed by Fleckenstein A, Rona G, Vol 6, Urban Schwarzenberg, München, Berlin, Wien, p 439,1975

25. Kent SP: Diffusion of plasma proteins into cells : a manifestation of cell injury in human myocardial ischemia. Am J Pathol 50:623, 1967

26. Fishbein MC, Meerbaum S, Rit J, Lando U, Kanmatsuse K, Mercier JC, Corday E, Ganz W: Early phase acute myocardial infarct size quantification. Validation of the triphenyl tetrazolium chloride tissue enzyme staining technique. Am Heart J 101: 593, 1981

27. Reimer KA, Lowe JE, Rasmussen MM, Jennings RB: The wave front phenomenon of ischemic cell death myocardial infarct size vs duration of coronary occlusion in dogs. Circulation $56: 786,1977$

28. Carle BN: Autofluorescence in the identification of myocardial infarcts. Human Pathol 12: 643,1980 